\title{
Determinants of patient delay in seeking treatment among pulmonary tuberculosis cases in a government specialist hospital in Ibadan, Nigeria
}

\author{
A.A. FATIREGUN* and C.C. EJECKAM \\ Department of Epidemiology, Medical Statistics and Environmental Health, Faculty of Public Health, College \\ of Medicine, University of Ibadan, Ibadan, Nigeria
}

\begin{abstract}
Patients delay in seeking care increases the transmission of pulmonary tuberculosis and hence the burden of the disease. This study investigates the pattern and determinants of patients delay in seeking treatment among pulmonary tuberculosis cases attending a Government Chest Clinic in Ibadan, Nigeria. A descriptive cross sectional study was employed. A face to face interview of 102 newly diagnosed tuberculosis patients at the clinic was conducted using a structured questionnaire. The mean age of respondents was $45.4 \pm 13.5$ years and $61(59.8 \%)$ were females. The overall median delay in seeking treatment among study subjects was 60 days (range 3 to 180 days), with $61.8 \%$ patients delaying for more than 30 days. Binary logistic regression model showed that female sex $(\mathrm{OR}=5.3)$, place of residence $(\mathrm{OR}=3.9)$, outside Ibadan vs. within Ibadan), age group $>45$ vs. $\leq 45$ years $(\mathrm{OR}=2.4)$ and reported stigma $(\mathrm{OR}=7.6)$ were significantly associated with longer patients delay. The results showed that delay among patients in seeking care is common and some groups of patients may be experiencing problems in seeking care in our environment.
\end{abstract}

Key words: tuberculosis, patient delay, determinants, DOT, Nigeria

\section{Introduction}

The burden of tuberculosis (TB) on public health is staggering, and has become of growing concern to stakeholders in recent times worldwide. In 1993, the World Health Organization (WHO) declared a state of global emergency for TB (WHO, 2006). By 1995, the directly observed treatment short-course (DOTs) strategy was established to achieve TB control (WHO, 2006; Maamari, 2008). Two of the key component of a good TB control programme are an early diagnosis and prompt institutions of effective treatment. This is especially important in patients with smear positive pulmonary tuberculosis (PTB) in order to reduce the transmission time of Mycobacterium TB in the communities. TB case detection is predicated on passive case finding using sputum smear microscopy (WHO, 2006; Mesfin et al., 2009). This is limited and has not been able to confront the growing burden and transmission of TB in most developing countries.

In Nigeria, TB is a serious public health concern with an estimated prevalence of 64,000 cases and an incidence of 283 cases of all forms of TB per 100,000 population (WHO, 2005; FMOH, 2007). This data placed the country as one of the highest TB burdened country in Africa and fifth highest in the world, among the 22 high TB burdened countries (WHO, 2005). Though Nigeria commenced the implementation of WHO's recommended DOTs strategy in 1993, and achieved $100 \%$ state-wide coverage in 2003, accessibility to DOTs services is still sub-optimal. This is worse among rural dwellers, most of who are poor and live several kilometres from DOTs service centres. As a result, the facts about TB are often

\footnotetext{
* Correspondence: Dr. Akinola A. Fatiergun; E-mail: Email: akinfati@yahoo.com
} 
misconstrued, resulting in poor knowledge of TB and stigmatization of TB patient (FMOH, 2007).

Delayed presentation is a major problem contributing to the high burden and transmission of TB (Mesfin et al., 2009). Patient delay, time from the onset of symptoms to first consultation to modern health care, is alarming prolonged with studies reporting from 2 to 12 months (Asch et al., 1998; Long et al., 1999; Madebo \& Lindtjorn, 1999; Demissie et al., 2002). Various cut -off limits have been ascribed depending on researcher's discretion (Asch et al., 1998; Long et al., 1999; Madebo \& Lindtjorn, 1999; Demissie et al., 2002; Olumuyiwa \& Babafemi, 2004). A study in Lagos, Nigeria defined patient delay as any delay beyond 30 days (Olumuyiwa \& Babafemi, 2004). Patients' decision on seeking health care, however, depend on several factors, some common to many countries and settings, and some context specific (Liefooghe et al., 1997; Asch et al., 1998; Long et al., 1999; Grover et al., 2006; Mesfin et al., 2009). Very little is known regarding the pattern of TB patients' delays and factors influencing it in our setting. Identifying the magnitude and risk factors of such delays will help improve TB control. This study was therefore, developed to assess the delay to seeking treatment and the risk factors for patient delays from the onset of symptoms to seeking care at the government specialist chest hospital which offers DOTs treatment in Ibadan, Southwest Nigeria.

\section{Materials and methods}

\section{Study setting}

The study was conducted at the chest clinic, Jericho Ibadan from $1^{\text {st }}$ June to 30 $0^{\text {th }}$ August, 2008. The clinic is a specialist chest clinic where diagnoses and treatment of TB and other related respiratory conditions, are carried out. The institution is located in Ibadan North Local Government Area of Oyo State but it is owned by the State government. The clinic is supported by the Damien Foundation, Belgium and works through the State Ministry of Health to support the National tuberculosis response. Passive case finding principle by the $\mathrm{WHO}$ and the guidelines for implementing community TB care in Nigeria is being followed in the clinic (WHO, 2005; FMOH, 2007).The clinic attends to an average of between 60 to 70 patients monthly, and is open for services' Mondays to Saturdays. It is the largest designated DOTs referral centre in the State. The clinic was purposively selected as the study site considering the large number of patients seen on average per month and the feasibility of implementing the study.

\section{Study design}

The study was cross sectional in design, involving a consecutive sampling of PTB patients accessing care and treatment at the study site.

\section{Study participants}

The study subjects were all newly diagnosed PTB patients, who had started taking treatments one week before or within the study period. Non-ambulatory patients were excluded. Informed verbal consent was sought from all the participants. Confidentiality of information was also maintained. Ethical approval for the study was sought from the State Ministry of Health ethics committee. 


\section{Data collection}

An interviewer administered semi-structured questionnaire was used to elicit relevant responses from study participants. The questionnaire sought information about the demographics, socio-economic characteristics, experience of stigma, and knowledge of TB among respondents. Others included disease history and health care seeking experiences of the subjects including duration from the onset of symptoms to obtaining a TB diagnosis. Face validation of the instrument was done through peer review and pretesting. In this study patient delay was defined as the duration from the onset of cough to the first visit to the clinic. A cut off of 30 days was used to denote prolong delay.

\section{Data analysis}

Data was serially coded, entered, cleaned and analyzed using the SPSS version 15 software package. The duration of diagnostic delay was skewed, so medians and range of values were reported. The proportion of subjects with more than 30 days delay was estimated. Bivariate tests; Chi-square, Fishers' exact and the Student $t$ tests were used as appropriate to identified variables that were associated with prolonged delay. Variables with $P<0.2$ were entered into a binary logistic regression model to identify the risk factors of prolong delay by eliminating confounding effect among potential risk factors. Odd ratios (OR) and their $95 \%$ confidence intervals $(\mathrm{CI})$ were used as estimates of relative risks.

\section{Results}

\section{Sociodemographic characteristics of the study participants}

A total of 102 new smear positive PTB patients were enrolled in the 3 month study period, of which $41(40.2 \%)$ were males and $61(59.8 \%)$ were females. The mean age was $45.4 \pm 13.5$ years. Among the study subjects, 32 (31.4\%) lived outside Ibadan City. Occupationally, 40 $(39.2 \%)$ of respondents were self employed (farming and trading), 26 (25.5\%) were civil servants and $13(12.7 \%)$ were unemployed. Income distribution showed that $21(20.6 \%)$ did not have a defined income, 65(63.7\%) had a regular income of between US\$ 0.1 to $\leq 36$ per month and $16(15.7 \%)$ had income of $>$ US $\$ 36$ per month. Religious distribution shows two groups; Christianity (58.8\%) and Islam (41.2\%). With regards to education $2 \%$ were illiterates, $16.7 \%$ had completed primary education while $41.2 \%$ and $40.2 \%$ had completed secondary and tertiary education respectively. Approximately, 19.6\% of the respondents never married, while $60.8 \%$ were married at the time of the interview (Table 1 ).

\section{Patients delay}

The median delay from the onset of cough to first visit to the clinic was 60 days with a range of 3 to 180 days. The prevalence of prolong patient delay was $63(61.8 \%)$. Reasons given by respondents with prolonged delay included health facility too far $22.2 \%$, lack of awareness of DOTs service on time $12.7 \%$, and domestic work prevented coming on time $9.5 \%$. Majority (52.4\%) did not give any specific reason (Table 2).

\section{Knowledge and sources of information about TB among study participants}

The overall mean knowledge score was $8.5 \pm 1.3$ on an 18 -point scale. There was no significant difference in the mean knowledge score of those who had prolonged delay (8.6 \pm 1.4$)$, and those who did not $(8.4 \pm 1.2) P=0.542$ (Table 3). Respondents' first source of information about TB and DOTs were as follows; $38.2 \%$ of respondents heard from the mass 
media, radio and television, $20 \%$ from health workers, $18.2 \%$ heard from previously treated TB patients, $10.9 \%$ from family members while $12.7 \%$ from friends.

Table 1: Socio-demographic status of the patients

\begin{tabular}{|c|c|c|c|c|c|c|c|}
\hline \multirow[t]{2}{*}{ Variables } & \multirow[t]{2}{*}{ Category } & \multicolumn{2}{|c|}{$\begin{array}{l}\text { Delay duration } \\
\geq 30 \text { days }\end{array}$} & \multicolumn{2}{|c|}{$<30$ days } & \multicolumn{2}{|c|}{ Total } \\
\hline & & $\mathrm{n}$ & $\%$ & $\mathrm{n}$ & $\%$ & $\mathrm{~N}$ & $\%$ \\
\hline \multirow[t]{2}{*}{ Gender } & Male & 16 & 25.4 & 25 & 64.1 & 41 & 40.2 \\
\hline & Female & 47 & 74.6 & 14 & 35.9 & 61 & 59.8 \\
\hline \multirow[t]{6}{*}{ Occupation } & Self employed & 32 & 50.8 & 8 & 20.5 & 40 & 39.2 \\
\hline & Unemployed & 9 & 14.3 & 4 & 10.3 & 13 & 12.7 \\
\hline & Civil servants & 8 & 12.7 & 18 & 46.2 & 26 & 25.5 \\
\hline & Private employee & 8 & 12.7 & -- & -- & 8 & 7.8 \\
\hline & Retired & 3 & 4.8 & 7 & 17.9 & 10 & 9.8 \\
\hline & Others & 3 & 4.8 & 2 & 5.1 & 5 & 4.9 \\
\hline \multirow[t]{4}{*}{ Education } & Informal & 2 & 3.2 & -- & -- & 2 & 2.0 \\
\hline & Primary & 15 & 23.8 & 2 & 5.1 & 17 & 16.7 \\
\hline & Secondary & 26 & 41.3 & 16 & 41.0 & 42 & 41.2 \\
\hline & Tertiary & 20 & 31.7 & 21 & 53.8 & 41 & 40.2 \\
\hline \multirow[t]{3}{*}{ Marital status } & Single & 9 & 14.3 & 11 & 28.2 & 20 & 19.6 \\
\hline & Married & 44 & 69.8 & 18 & 46.2 & 62 & 60.8 \\
\hline & Widowed & 10 & 15.8 & 10 & 25.6 & 20 & 19.6 \\
\hline \multirow[t]{2}{*}{ Religion } & Christianity & 44 & 69.8 & 16 & 41.0 & 60 & 58.8 \\
\hline & Islam & 19 & 30.2 & 23 & 59.0 & 42 & 41.2 \\
\hline \multirow[t]{4}{*}{ Tribe } & Yoruba & 38 & 60.3 & 31 & 79.5 & 69 & 67.6 \\
\hline & Ibo & 10 & 15.9 & -- & -- & 10 & 9.8 \\
\hline & Hausa & 2 & 3.2 & 6 & 15.4 & 8 & 7.8 \\
\hline & Others & 13 & 20.6 & 2 & 5.1 & 15 & 14.7 \\
\hline \multirow[t]{2}{*}{ Residence } & Within Ibadan & 37 & 58.7 & 33 & 84.6 & 70 & 68.6 \\
\hline & Outside Ibadan & 26 & 41.3 & 6 & 15.4 & 32 & 31.4 \\
\hline \multirow[t]{2}{*}{ Age group } & $<45$ years & 27 & 42.9 & 25 & 64.1 & 52 & 51.0 \\
\hline & $\leq 45$ years & 36 & 57.1 & 14 & 35.9 & 50 & 49.0 \\
\hline \multirow[t]{3}{*}{ Income } & Undefined & 12 & 19.1 & 9 & 23.1 & 21 & 20.6 \\
\hline & US\$0.1 - $\leq 36$ & 41 & 65.1 & 24 & 61.5 & 65 & 63.7 \\
\hline & >US\$ 36 & 10 & 15.8 & 6 & 15.3 & 16 & 15.7 \\
\hline
\end{tabular}

Table 2: Reasons for delaying for more than 30 days before presenting for DOTs

\begin{tabular}{lll}
\hline Reasons & $\mathbf{N}$ & $\%$ \\
\hline Health facility too far & 14 & 22.2 \\
Lack of awareness of DOTs & 8 & 12.7 \\
Because of domestic work & 6 & 9.5 \\
Poor socio-economic condition & 2 & 3.2 \\
No specific reason & 33 & 52.4 \\
Total & 63 & 100 \\
\hline
\end{tabular}


Table 3: Knowledge of Respondents about Tuberculosis by patient delay

\begin{tabular}{|c|c|c|c|c|c|}
\hline \multirow[t]{2}{*}{ TB issues } & \multicolumn{2}{|c|}{$\begin{array}{l}\text { Delay } \\
\geq 30 \text { days } \\
\text { Correct } \\
\text { responses } \\
n=63\end{array}$} & \multicolumn{2}{|c|}{$\begin{array}{l}\text { Delay } \\
<30 \text { days } \\
\text { Correct } \\
\text { responses } \\
n=39\end{array}$} & \multirow[t]{2}{*}{$\begin{array}{l}P \\
\text { value }\end{array}$} \\
\hline & $\mathrm{n}$ & $\%$ & $\mathrm{n}$ & $\%$ & \\
\hline Have heard of TB before & 63 & 100 & 35 & 89.7 & ${ }^{*} 0.02^{+}$ \\
\hline Causes TB (Microbes) & 55 & 87.3 & 35 & 89.7 & $1.000^{+}$ \\
\hline Symptom of TB: Cough lasting more than three weeks & 55 & 87.3 & 31 & 79.5 & 0.292 \\
\hline Symptom of TB: Night sweat & 7 & 11.1 & 9 & 23.1 & 0.106 \\
\hline Symptom of TB: Weight loss & 19 & 30.2 & 9 & 23.1 & 0.436 \\
\hline Symptom of TB: Chest pain & 48 & 76.2 & 28 & 71.8 & 0.621 \\
\hline Symptom of TB: Loss appetite & 17 & 27.0 & 4 & 10.3 & 0.042 \\
\hline Symptom of TB: Fever & 22 & 34.9 & 15 & 38.5 & 0.718 \\
\hline Symptom of TB: General body weakness & 19 & 30.2 & 11 & 28.2 & 0.833 \\
\hline $\mathrm{TB}$ can be contracted from one person to another & 57 & 90.5 & 33 & 84.6 & $0.528^{+}$ \\
\hline $\begin{array}{l}\text { TB is transmitted by airborne contact with droplet nuclei } \\
\text { during coughing }\end{array}$ & 52 & 82.5 & 37 & 94.9 & $0.123^{+}$ \\
\hline There is association between HIV/AIDS and TB & 26 & 41.3 & 20 & 51.3 & 0.323 \\
\hline TB can be cured & 56 & 88.9 & 39 & 100.0 & $* 0.04^{+}$ \\
\hline Using of Anti-TB drugs is effective in treating TB & 51 & 81.0 & 28 & 71.8 & 0.282 \\
\hline Was awareness of free TB treatment & 30 & 47.6 & 25 & 64.1 & 0.105 \\
\hline Normal duration of DOTS therapy (months) & 6 & 9.5 & 0 & 0.0 & $0.079^{+}$ \\
\hline Regular taking of prescribed medicine help control/ cure TB & 63 & 100 & 39 & 100 & -- \\
\hline $\begin{array}{l}\text { You may discontinue DOTS once symptoms have cleared } \\
\text { even when prescribed treatment during has not been } \\
\text { completed }\end{array}$ & 13 & 20.6 & 4 & 10.3 & 0.172 \\
\hline Having loss of appetite before the first consultation & 24 & 38.1 & 4 & 10.3 & *0.002 \\
\hline Mean Knowledge score (Standard deviation) & & & & (1.2) & $0.542^{++}$ \\
\hline
\end{tabular}

+Fishers exact test; +†Student test otherwise Chi-square test; ${ }^{*}$ Significant association

\section{Factors associated with patient delay}

Table 4 showed the estimates of risk (OR and 95\% CI) for risk factors in the binary logistic regression model. Female sex $(\mathrm{OR}=5.3)$, place of residence, outside vs. within Ibadan $(\mathrm{OR}=3.9)$, age group $>45$ vs. $\leq 45(\mathrm{OR}=2.4)$, and experience of stigma $(\mathrm{OR}=7.6)$ were significantly associated with prolong patient delay.

Table 4: Binary Logistic Regression Analysis of risk factors for prolong patients delay

\begin{tabular}{llll}
\hline Independent Variables & Odds Ratio & \multicolumn{2}{c}{$\mathbf{9 5 \%}$ Confidence Interval } \\
\hline Experienced Stigma & 7.6 & 2.8, & 21.2 \\
Female sex & 5.3 & 1.1, & 14.1 \\
Residence & 3.9 & 1.3, & 12.1 \\
Christianity & 3.3 & 1.0, & 17.2 \\
Age $>$ 46 years & 2.4 & 1.0, & 15.0 \\
\hline
\end{tabular}

\section{Discussion}

The findings of this study suggest that there was a prolonged health care seeking for TB among TB patients after the onset of symptoms. The median delay of 60 days in this study 
was longer than the reported median of 10 days ( $\mathrm{Xu}$ et al., 2005), 12.5 days (Cheng et al., 2005), and 21 days (Wang et al., 2007), indicated in China but consistent with 7.7 weeks (Long et al., 1999), 60 days (Enwuru et al., 2002) or 8 weeks (Olumuyiwa \& Babafemi, 2004) found in Vietnam and Nigeria. However, the prevalence of delay among patients $(63 \%)$ found in this present study in Ibadan, Nigeria was lower compared with the previous prevalence of $83 \%$ (Olumuyiwa \& Babafemi, 2004) and 81\% (Enwuru et al., 2002) reported among TB patients in Lagos, Nigeria. The differences in peculiarities of the two cities, especially the complex socio-cultural and cosmopolitan milieu of Lagos, coupled with her large population density may have contributed to the observed difference. Reasons adduced by some respondents who had prolonged delay in seeking care in the present study; health facility too far, too busy, lack of awareness of DOTs services were similar to those reported among 800 new smear positive pulmonary TB patients in Syrian Arab Republic in a study to assess the diagnostic and treatment delays and their determinants (Mesfin et al., 2009).

Health care seeking is a complex process influenced by many external and internal factors. Although studies that have assessed health seeking among TB patients in relation to knowledge are not common, our findings in this study indicated that there was no relationship between prolonged delay and knowledge of causes, transmission routes, symptoms and curability of TB. This contrasts with the report of a study in Vietnam where a relationship was established (Hoa et al., 2003). However, unlike in the present study the knowledge of TB was generally low. For instance, about $82 \%$ of women and $74 \%$ of men did not know that TB is caused by a bacterium in that study, whereas in the present study only $11.8 \%$ did not know this fact. Although our finding indicated that mass media (radio and television) was the major source of health information about TB among the TB patients, it has been reported that promoting health education through radio and television may not be enough if the wish is to reach and influence potential TB cases. This is because globally TB is most common to the socioeconomically disadvantaged, and if equal opportunities to education and media access are not forthcoming, health communication may fail despite a good intention (Hoa et al., 2003).

Several factors were found to be associated with prolonged delay on a logistic regression model, this included, female sex, place of residence, age group $>45$, Christian religion and experience of stigma. The association of prolonged delay with female sex collaborates with findings by some African studies (Lawn et al., 1998; Pronyk et al., 2001) and studies elsewhere (Yamasaki-Naagawa et al., 2001; Giasuddin \& Jalaluddin, 2004). This finding, however, conflicts with other studies in Ethiopia (Mesfin et al., 2009), Vietnam (Long et al., 1999), Lagos, Nigeria (Olumuyiwa \& Babafemi, 2004) and in India (Rajeswari et al, 2002), where all showed no statistical significant association between sex and prolong patient delay. Females' tendency to delay has been attributed to their limited decision making power, engagement in domestic work, unemployment and facility too far (Yamasaki-Naagawa et al., 2001; Mesfin et al., 2009). Moreover, in line with previous reports (Madebo \& Lindtjorn, 1999; Demissie et al., 2002; Rajeswari et al., 2002) rural residency (resident outside Ibadan) was significantly associated with prolonged patient delay. Poor access to healthcare in terms of travel time from patient's areas of residences to public facilities is closely related to income level. The lack of association of low income with prolonged delay in this study could be due to is its interaction with patient area of residence.

Using the mean age of 45 years as cut off, we found that those who are above this age have a 2.4 fold increase in odds of prolonged delay compared with those below this age group. This is consistent with the findings in India (Rajeswari et al., 2002), which showed, 
using the same patient delay cut-off $>30$ days, that older patients ( $>45$ years) delayed health seeking for TB following onset of symptoms. The study adduced preoccupations with family commitments as the likely reasons why older TB patients delayed care seeking. The odd of patient delay for Christians was about 3.3 fold higher compared with Muslims. This perhaps could be attributable to the "faith cures all things syndrome" which is highly prevalent among modern day Christians in our society today. A study in Ethiopia has documented a related finding where the use of holy water by followers of an Orthodox Christianity as an initial treatment was identified as a cause of patient delayed presentation in areas where public health facilities are remotely located (Mesfin et al., 2009). Lastly, we found that prolonged patient delay was common to those who reported having experienced any form of stigma. Studies have reported that stigma attached with TB often deters patients from seeking early treatment (WHO, 2005; Godfrey-Faussett, 2002). With the spread of HIV, TBrelated stigma has been heightened in sub Saharan Africa (Banerjee et al., 2000; Lawn, 2000).

There are obvious limitations in this study. The study relied entirely on responses as given by respondents and only hope for objective and honest responses. For instance, we were unable to determine the time of onset of symptoms in all patients in the study. Information depended on self reports based on recall history and individual variations in perception of disease. We, however, limited participants to recently diagnosed cases to minimize recall bias. Moreover, questionnaires were pretested to make sure that all questions were understandable.

In conclusion, our study showed that delay among patients in seeking care is common and some groups of patients experienced problems in seeking care in our environment. Public health education targeting the identified groups may go a long way in reducing patient delay in accessing DOTs services.

Received 22 September, 2009

Revised 25 March 2010

Accepted 26 March 2010

\section{References}

Asch, S., Leake, B., Anderson, R. \& Gelberg, L. (1998) Why do symptomatic patients delay obtaining care for tuberculosis? American Journal of Respiratory Critical Care Medicine $157,1244-1248$.

Banerjee, A., Harris, A.D., Nyirenda, T. \& Salaniponi, F.M. (2000) Local perceptions of tuberculosis in rural districts of Malawi. International Journal of Tuberculosis and Lung Disease 4, 1047-1051.

Cheng, G., Tolhurst, R., Li, R.Z., Meng, Q.Y. \& Tang, S. (2005) Factors affecting delays in tuberculosis diagnosis in rural China: a case study in four counties in Shandong Province. Transactions of the Royal Society of Tropical Medicine and Hygiene 99, 355-362.

Demissie, M., Lindtjorn, B. \& Berhane, Y. (2002) Patient and health service delay in the diagnosis of pulmonary tuberculosis in Ethiopia. BMC Public Health 2, 23.

Enwuru, C.A., Idigbe, E.O., Ezeobi, N.V. \& Otegbeye, A.F. (2002) Care-Seeking, Behavioural Patterns, Awareness and Diagnostic Processes in Patients with Smear- and CulturePositive Pulmonary Tuberculosis in Lagos, Nigeria. Transactions of the Royal Society of Tropical Medicine and Hygiene 96, 614-616. 
FMOH (2007) Guidelines for Implementing Community Tuberculosis Care in Nigeria. Federal Ministry of Health, National Tuberculosis and Leprosy Control Programme, Abuja, Nigeria.

Giasuddin, A. \& Jalaluddin, A. (2004) Gender Difference in treatment seeking behaviors of tuberculosis cases in rural communities of Bangladesh. National TB Control Programme, Ministry of Health Bangladesh.

Godfrey-Faussett, P., Kaunda, H., Kamanga, J., van Beers, S., van Cleeff, M., KumwendaPhiri, R. \& Tihont, V. (2002) Why do patients with a cough delay seeking care at Lusaka urban health centres? A health systems research approach. International Journal of Tuberculosis and Lung Disease 6, 796-805.

Grover, A., Kumar, R. \& Jindal, K. (2006) Socio-demographic determinants of treatment seeking behavior among chest symptomatic in India. India Journal of Community Medicine 31,145 -149.

Hoa, N.P., Thorson, A.E.K., Long, N.H. \& Diwan, V.K. (2003) Knowledge of tuberculosis and associated health-seeking behavior among rural Vietnamese adults with a cough for at least three weeks. Scandinavian Journal of Public Health 31, 1-7.

Lawn, A.D. (2000) Tuberculosis in Ghana: social stigma and compliance with treatment. International Journal of Tuberculosis and Lung Disease 4, 1190-1191.

Lawn, S.D., Afful, B., Acheampong, J.W. (1998) Pulmonary tuberculosis: diagnostic delay in Ghanaian adults. International Journal of Tuberculosis and Lung Disease 2, 635-640.

Liefooghe, R., Baliddawa, J., Kipruto, E.M., Vermeire, C., De Munynck, A.O. (1997) From their own perspective. A Kenyan community's perception of tuberculosis. Tropical Medicine and International Health 2, 809-821.

Long, N.H., Johansson, E., Lonnroth, K., Eriksson, B., Winkvist, A. \& Diwan, V.K. (1999) Longer delays in tuberculosis diagnosis among women in Vietnam. International Journal of Tuberculosis and Lung Disease 3, 388-393.

Maamari, F. (2008) Case-finding tuberculosis patients: diagnostic and treatment delays and their determinants. Eastern Mediterranean Health Journal 14, 531-545.

Madebo, T. \& Lindtjorn, B. (1999) Delay in treatment of pulmonary tuberculosis: an analysis of symptom duration among Ethiopia patients. Medscape Journal of Medicine 18:e6.

Mesfin, M.M., Newell, J.N., Walley, J.D., Gessessew, A. \& Madeley, R.J. (2009) Delayed consultation among pulmonary tuberculosis patients: a cross sectional study of 10 DOTS districts of Ethiopia. BMC Public Health 9:53.

Olumuyiwa, O. \& Babafemi, J. (2004) Patterns of delay among pulmonary tuberculosis patients attending a Lagos Chest clinic, Lagos Nigeria. BMC Public Health 4:18.

Pronyk, R.M., Makhubele, M.B., Hargreaves, J.R., Tollman, S.M. \& Hausler, H.P. (2001) Assessing health seeking behavior among tuberculosis patients in rural South Africa. International Journal of Tuberculosis and Lung Disease 5, 619-627.

Rajeswari, R., Chandrasekaran, V., Suhadev, M., Sivasubramaniam, S., Sudha, G., Renu, G. (2002) Factors associated with patient and health system delays in the diagnosis of tuberculosis in South India. International Journal of Tuberculosis and Lung Disease 6, 789-795.

Wang, W., Jiang, Q., Abdullah, A.S.M. \& Xu, B. (2007) Barriers in accessing to tuberculosis care among non residents in Shanghai: a descriptive study of delays in diagnosis. European Journal of Public Health 17, 419-423.

WHO (2006 Global Tuberculosis Control: Surveillance, Planning, Financing. WHO Report 2006, World Health Organization, Geneva, Switzerland. 
WHO (2005) Global Tuberculosis Control: Surveillance, Planning, Financing. WHO Report 2005, Geneva, Switzerland.

Xu, B., Jiang, Q.W., Xiu, Y., Diwan, V.K. (2005) Diagnostic delays in access to tuberculosis care in countries with or without the National Tuberculosis Control Programme in rural China. International Journal of Tuberculosis and Lung Disease 9, 784-790.

Yamasaki-Naagawa, M., Ozasa, K., Yamada, N., Osuga, K., Shimouchi, A., Ishikawa, N. \& Mori, T. (2001) Gender difference in delays to diagnosis and health care seeking behaviour in a rural area of Nepal. International Journal of Tuberculosis and Lung Disease 5, 24-31. 